\title{
M2 Macrophage Marker Chitinase 3-Like 2 (CHI3L2) Associates With Progression of Conventional Renal Cell Carcinoma
}

\author{
CSABA PUSZTAI ${ }^{1}$, MARIA V. YUSENKO ${ }^{1}$, DANIEL BANYAI ${ }^{1}$, ARPAD SZANTO $^{1}$ and GYULA KOVACS ${ }^{1,2}$ \\ ${ }^{1}$ Department of Urology, Medical School, University of Pecs, Pecs, Hungary; \\ ${ }^{2}$ Department of Biochemistry, University of Muenster, Muenster, Germany; \\ ${ }^{3}$ Medical Faculty, Ruprecht-Karls-University, Heidelberg, Germany
}

\begin{abstract}
Background/Aim: In spite of early detection, appoximately $15 \%$ of the small renal cell carcinomas (RCC) will develop metastasis within 5 years follow-up. The aim of this study was to identify new biomarkers to estimate the postoperative relapse of the most common conventional RCC. Patients and Methods: Tissue multi arrays of conventional RCC without metastasis at the time of operation from a cohort of 634 patients were analysed by immunohistochemistry for expression of the chitinase 3-like protein 2 (CHI3L2). Cancer specific survival of patients was estimated with Kaplan-Meier analysis, univariate and multivariate Cox regression models. Results: Kaplan-Meier analysis estimated a shorter cancer-free survival for patients with CHI3L2 positive tumors. In multivariate analysis, the CHI3L2 positivity associated with a 3.5 times higher risk for tumor relapse $(p<0.001)$. Conclusion: Expression of CHI3L2 in tumor cells of conventional RCC define a group of patients at high risk for postoperative progression.
\end{abstract}

The widespread use of imaging techniques in routine diagnosis results in detection of a growing number of renal cell carcinomas (RCCs) confined to the kidney $(1,2)$. However, in spite of the early detection, appoximately $10-15 \%$ of the small RCCs operated with curative intent will develop metastasis within 5 years follow-up. Therapies targeting VEGF and mTOR pathways or recently used biologic and immunmodulatory therapies can prolong the life of patients

Correspondence to: Gyula Kovacs, Department of Urology, Medical School, University of Pecs, Munkacsy M. u. 2, H-7621 Pecs, Hungary. Tel: +36 72507334, Fax: +36 72242374, e-mail: g.kovacs@gmx.de, gyula.kovacs@urz.uni-heidelberg.de ORCID: 0000-0003-2890-3781

Key Words: Conventional renal cell carcinoma, tissue microarray, CHI3L2, immunohistochemistry, postoperative tumor relapse. having metastatic disease. Therefore, there is a need for biomarkers to estimate postoperative tumor relapse. The close follow-up of these patients enhances the chance to detect metastasis as early as possible and start targeted therapy.

By applying global gene expression analysis using the Affymetrix array we have identified increased expression of several genes including chitinase 3-like protein 2 (CHI3L2), in most commonconventional RCCs with rapid progression leading to death of patients within 3 years after operation. The CHI3L2 expression was first demonstrated in chondrocytes and synoviocytes and CHI3L2 is recognized as a specific biomarker of progression of osteoarthritis $(3,4)$. There is a well documented correlation between expression of another chitinase (CHI3L1) and tumor progression (5-9). However, no data are available on the possible correlation between CHI3L2 expression and biological behaviour of conventional RCC.

The aim of this study was to analyse the expression of CHI3L2 in a cohort of conventional RCCs confined to the kidney at the time of operation and estimate the predictive value of its expression for postoperative tumor relapse. To achieve our goal, 634 clinically localized conventional RCCs at the time of operation were subjected to CHI3L2 immunohistochemistry.

\section{Patients and Methods}

Affymetrix array analysis. For gene expression analysis we used RNA isolated from 12 conventional RCCs leading to death of patients within 3 years of follow up and from another 12 tumours without progression during 8 years follow up. Gene expression analysis was carried out using the Affymetrix Human Genome U133 Plus 2.0 array as described earlier (10). Differentially expressed genes were identified by using the Gene Set Enrichment Analysis (11). Data of the expression profile have been deposited in the NCBI Gene Expression Omnibus under the accession number GSE11151.

Clinical data and tissue samples. A total of 634 patients who underwent radical or partial nephrectomy for conventional RCC between 2000 and 2013 at the Department of Urology, University 
of Pecs, Hungary were enrolled in this study. None of the patients had detectable metastatic disease at the time of operation. Data on regular follow-up, tumor relapse and tumor specific death were obtained from the Renal Tumor Registry of the Department of Urology. Follow-up was defined as the time from operation until the last recorded examination or cancer specific death. Patients who died from disease other than RCC were excluded from this study. Preoperative clinical staging included abdominal and chest computed tomography scans (CT). Bone scans and brain CT scans were performed only when indicated by clinical signs. The presence of nodal involvement was confirmed by histology, whereas distant metastases by radiographic examination. Patients were followed up every 6 months during the postoperative period, by abdominal ultrasound and measurement of serum creatinine and eGFR, and yearly by $\mathrm{CT}$.

The histological diagnosis and TNM classification were reevaluated by a genitourinary pathologist $(\mathrm{GK})$ according to the Heidelberg and TNM classification systems by applying a 3 scaled tumor grading system $(12,13)$. The collection and use of all tissue samples for this study was approved by the Ethics Committee of the University Pecs, Hungary (No. 5343/2014)

Tissue microarray (TMA) and immunohistochemistry. Representative tumor areas were marked in H\&E stained slides of conventional RCCs. Two to five biopsies were obtained from each tumor, corresponding to areas of different morphology and/or tumor grade. TMA was constructed by one of the authors (GK) using a Manual Tissue Arrayer (MTA1, Beecher Instruments, Inc., Sun Prairie, WI, USA) and $0.6 \mathrm{~mm}$ core biopsies.

Normal adult kidneys and TMAs containing conventional RCCs were used for immunohistochemistry. After dewaxing and rehydration, the $4-\mu \mathrm{m}$ thick sections were subjected to heat-induced epitope retrieval in citrate buffer, $\mathrm{pH} 6.0$ in 2100-Retriever (PickCell Laboratories, Amsterdam, The Netherlands). We used the EnVision FLEX System (DAKO, Glostrup, Denmark) for immunohistochemistry. Endogenous peroxidase was blocked with the Peroxydase-Blocking Reagent (DAKO) for $10 \mathrm{~min}$ at room temperature. The slides were incubated for 1 hour at room temperature with polyclonal rabbit anti-CHI3L2 antibody raised against the amino acids $27-374$ of the CHI3L2 protein (Cat. Nunmber PA5-21548, ThermoFisher Scientific, Budapest, Hungary) at 1:200 dilution. HRP conjugated secondary antibody (DAKO) was applied for $20 \mathrm{~min}$ and color was developed using the AEC substrate (DAKO). Tissue sections were counterstained with Mayer's haematoxylin (DAKO). Normal adult kidney included in the TMA was used as positive control. For the negative control, the primary antibody was omitted. The result was scored as membranous, cytoplasmic or negative staining. As more than $90 \%$ of tumor cells were positive at least in one of the core biopsies, no counting of positive cells was necessary. In cases with different staining in multiple biopsies from the same tumor, the positive staining was taken into account.

Statistical analysis. Correlations between categorical variables were estimated with Fisher's exact test. Estimates of the cumulative survival distributions were calculated by the Kaplan-Meier method, and the differences between the groups were compared using the log-rank test. The significance of clinical-pathological variables was evaluated using the univariate and multivariate Cox proportional hazard regression model. Analysis was performed using IBM SPSS
Table I. Association of CHI3L2 expression with clinical and pathological parameters $(n=634)$.

\begin{tabular}{|c|c|c|c|c|}
\hline & \multirow{2}{*}{$\begin{array}{l}\text { Nr. of cases } \\
\quad(634)\end{array}$} & \multicolumn{2}{|c|}{ CHI3L2 expression } & \multirow[t]{2}{*}{$p$-Value } \\
\hline & & $\begin{array}{l}\text { Negative } \\
(502)\end{array}$ & $\begin{array}{l}\text { Positive } \\
\text { (132) }\end{array}$ & \\
\hline \multicolumn{4}{|l|}{ Gender } & 0.020 \\
\hline Male & 371 & 282 & 89 & \\
\hline Female & 263 & 220 & 43 & \\
\hline \multicolumn{4}{|l|}{ Status } & $<0.001$ \\
\hline AWOD & 534 & 465 & 69 & \\
\hline PTP & 100 & 37 & 63 & \\
\hline \multicolumn{4}{|l|}{ Tumor size } & $<0.001$ \\
\hline$<4 \mathrm{~cm}$ & 251 & 222 & 29 & \\
\hline $4-7 \mathrm{~cm}$ & 251 & 193 & 58 & \\
\hline$>7 \mathrm{~cm}$ & 132 & 87 & 44 & \\
\hline \multicolumn{5}{|l|}{ T-Stadium } \\
\hline \multicolumn{5}{|l|}{$<0.001$} \\
\hline pT1 & 477 & 405 & 72 & \\
\hline pT2 & 87 & 64 & 23 & \\
\hline pT3 & 70 & 33 & 37 & \\
\hline Tumor grade & & & & $<0.001$ \\
\hline G1 & 430 & 386 & 44 & \\
\hline G2 & 158 & 101 & 57 & \\
\hline G3 & 46 & 15 & 31 & \\
\hline Tumor stage & & & & $<0.001$ \\
\hline I & 473 & 403 & 70 & \\
\hline II & 84 & 63 & 21 & \\
\hline III & 77 & 36 & 41 & \\
\hline
\end{tabular}

AWOD: Alive without disease; PTP: postoperative tumor progression.

Statistics v.25 for Windows (Inc. Chicago IL, USA). p-Value $<0.05$ was considered as the limit of statistical significance.

\section{Results}

Patients. A total of 634 patients diagnosed with conventional RCC confined to the kidney were included in the study. The mean age of patients was $61.4 \pm 11.2$ and $371(58 \%)$ of the patients were male and $263(42 \%)$ female. The mean followup time of patients was $73.53 \pm 4.6$ months. During the follow-up 100 (16\%) patients developed metastasis or died due to metastatic cancer. The pertinent clinical and pathological parameters are shown in Table I.

Expression of CHI3L2 in conventional RCC. Global gene expression analysis revealed an upregulation of CHI3L2 RNA exclusively in conventional RCC with rapid progression (Figure 1A). Immunohistochemical analysis detected CHI3L2 expression exclusively in proximal tubular cells of normal adult kidney. A strong membrane attenuated expression of CHI3L2 was seen at the luminar surface of the tubular cells whereas cytoplasm displayed no or only weak expression 

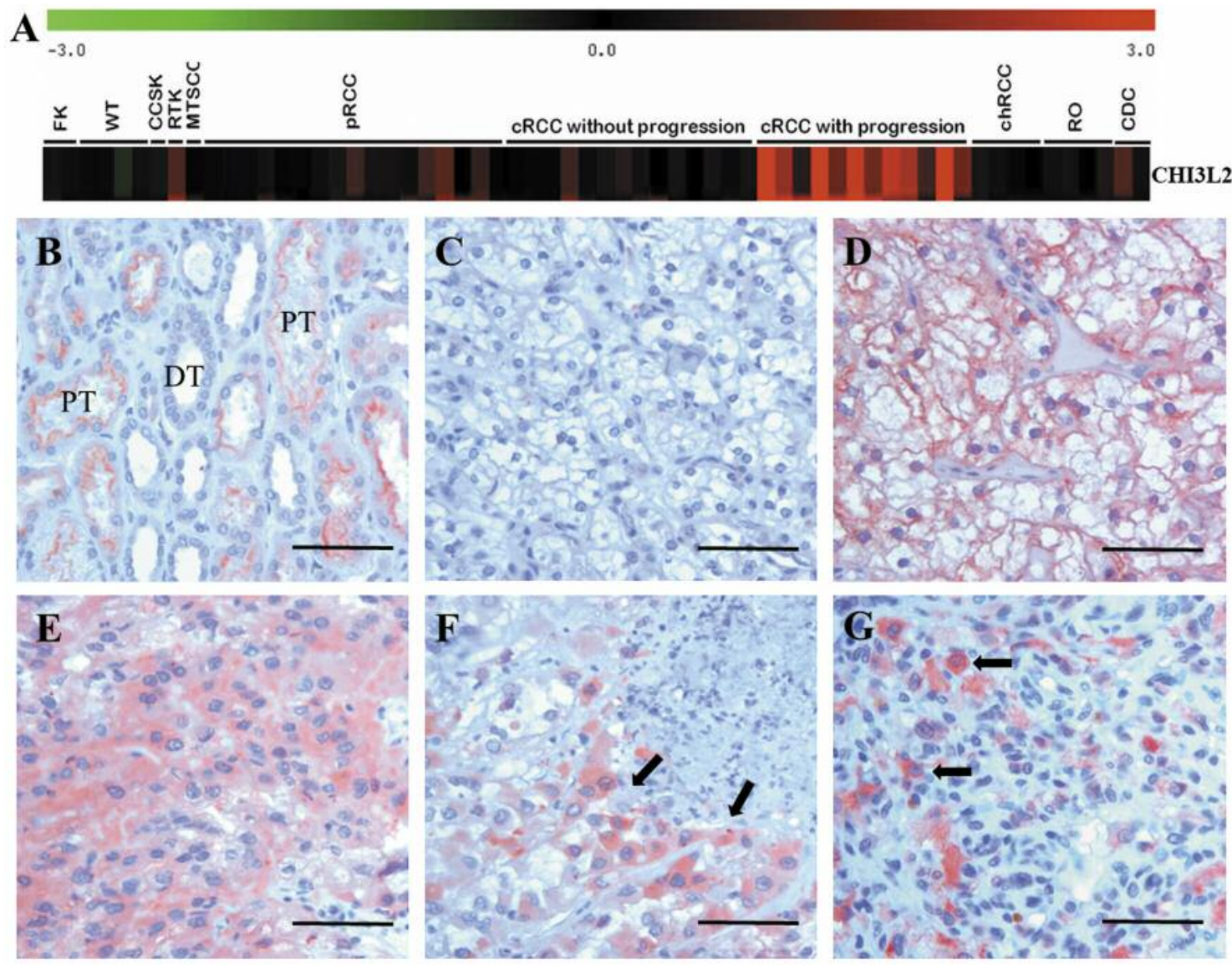

Figure 1. Expression of CHI3L2 protein in conventional RCC. A) Global gene expression analysis revealed a preferential expression of CHI3L2 in rapidly progressing conventional RCC.B) Expression of CHI3L2 at the luminar membrane of proximal tubular cells (PT-proximal tubules, DTdistal tubules). C) Negative reaction with CHI3L12 antibody. D) Strong membrane attenuated expression in "clear cell" conventional RCCs. E) diffuse cytoplasmic expression of CHI3L2 protein. F) Strong CHI3L2 protein expression in tumor cells around a small necrotic area (arrows). G) CHI3L2 positive cells within a tumor stroma (arrows). Scale bar: $50 \mu \mathrm{m}$.

(Figure 1B). The vast majority of conventional RCC (502 of 634) were negative for CHI3L2 immunoreaction in each core biopsy (Figure 1C). Among the negative tumors both "clear cell" as well as "granular cell" conventional RCC were observed. A strong membrane attenuated and submembranous expression or cytoplasmic expression of CHI3L2 protein was seen in at least one of the core biopsies of 132 tumors (Figure $1 \mathrm{D}$ and E). Of interest, we observed strong CHI3L2 immunoreaction in tumor cells surrounding small necrotic tumor areas (Figure 1F). Tumor associated macrophages displayed strong CHI3L2 staining in the inflammatory stroma of aggressive growing tumors (Figure 1G).

Expression of CHI3L2 correlates with progression of conventional $R C C$. First, we evaluated the results of immunhistochemistry by Kaplan-Meier analysis according to negative, membranous and cytoplasmic positive cases and found no significant difference between membranous and cytoplasmic expression. Therefore, we analysed both cytoplasmic and membrane attenuated expression together as positive. The association between CHI3L2 protein expression and clinical and pathological parameters is summarized in Table I. Expression of CHI3L2 showed a significant correlation with tumor relapse, size, grade and $\mathrm{T}$ classification. The Kaplan-Meier survival analysis using the log-rank test indicated a short disease-free survival for patients with CHI3L2 positive tumors (Figure 2). The 5-year survival rate for the CHI3L2 positive and negative group was $59.0 \%$ and $95,4 \%$, respectively. Univariate analysis showed a significant association between size, T-classification, grade, and stage of tumors with CHL3L2 expression. Multivariate analysis was also performed to assess the independent prognostic value of CHI3L2expression in relation to known clinicopathological prognostic variables. Positive CHI3L2 


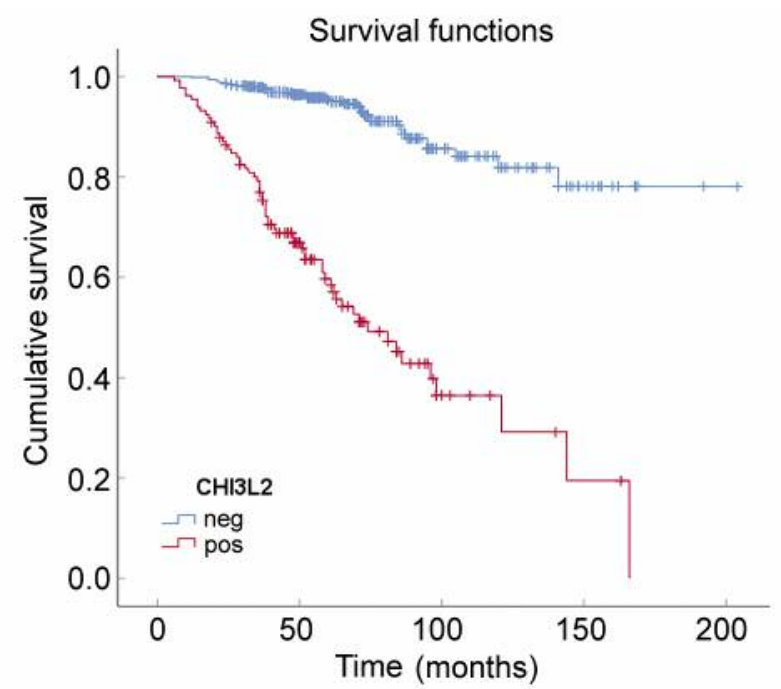

Figure 2. Kaplan-Meier estimates confirm the significant prognostic value of CHI3L2 expressionin 634 patientswith conventional RCC. The 5-year tumor-free survival rate for the CHI3L2 positive and negative group were $59.0 \%$ and $95.4 \%$, respectively (Log rank (Mantel-Cox), $p<0.001$ ).

expression showed a significant association with tumor grade (G2 and G3, $p=0.004, p=0.003$, respectively). The correlation between CHI3L2 positivity and postoperative relapse was statistically significant, marking a group of patients with more than 3 times higher risk for metastatic disease $(\mathrm{RR}=-3.49 ; 95 \% \mathrm{CI}=-2.21-5.51 ; p<0.001)$.

\section{Discussion}

In this study, detected cell membrane attenuated or cytoplasmic expression of CHI3L2 protein in 132 out of 634 conventional RCC confined to the kidney at the time of operation. Kaplan-Meier analysis and Cox proportional regression model revealed a significant correlation between CHI3L2 expression in tumor cells and postoperative tumor relapse. Multivariate analysis indicated that the expression of CHI3L2 by tumor cells was a significant independent factor of conventional RCC progression. Therefore, CHI3L2 is a valuable biomarker to stratify patients with conventional RCC into low- and high-risk categories.

The chitinase-like proteins belong to the glycoside hydrolase 18 family and exist in two isoforms, a major $50 \mathrm{kDa}$ and a truncated $39 \mathrm{kDa}$ isoform (14). The C-terminal domain of the truncated $39 \mathrm{kDA}$ isoform has the capacity to bind to chitin, whereas the $50 \mathrm{kDA}$ form is secreted by macrophages (15). The CHI3L2 binds to chytooligo-sacharides but it has lost the ability to hydrolyse them (16). CHI3L2 mRNA has been detected in lung, heart, and glioblastoma, but not in brain, spleen, or pancreas $(3,17)$. CHI3L2 is also expressed in macrophages stimulated by IL-4 and TGFb (18).
A recent study on human embryonic kidney cells (HEK293) and human glioblastoma (U87 MG) cells has shown that CHI3L2 signal transduction was regulated through the phosphorylation of ERK1/ERK2 kinases (19). CHI3L2 has been reported to enhance cell proliferation, colony formation and type II collagen expression at least in mouse chondrogenic ATDC5 cells (20). Recently, CHI3L2 has been identified as a pro-angiogenic and monocyte recruiting factor, and its elevated expression has been shown to be predictive for increased risk of distant metastases and poor response to neoadjuvant therapy of breast cancer (21). CHI3L2 has the ability to induce the migration of monocytes (22). The absence of clinical response to the therapy is associated with the presence of the M2 positive macrophage phenotype (22). Macrophages secret chitinase like proteins including CHI3L2 (9). Recruitment of monocytes into tumor stroma is a critical process in all steps of tumor progression and may modulate the response to therapy $(23,24)$. In our study, expression of CHI312 was detected not only in the tumor cells but also in macrophages recruited to the tumor stroma.

An elevated level of expression and secretion of another chitinase 3-like protein 1, CHI3L1 (YKL-40) has already been correlated with poor outcome and short disease free survival of glioblastoma, breast, colorectal, lung, prostate, bladder, stomach and endometrial cancers (5-9). We showed, in this study, that positive immunstaining with CHI3L2 antibody is significantly associated with conventional RCC progression. We suggest that CHI3L2 expression can be used to identify a subset of conventional RCC with high-risk of disease progression and to optimize active surveillance and timely adjuvant therapy.

\section{Conflicts of Interest}

Authors have no conflicts of interest to declare.

\section{Authors' Contributions}

CP and GK designed the research study, GK constructed the TMA, $\mathrm{CP}$ and DB performed the immunohistochemistry, CP and MVY analysed the data. $\mathrm{CP}$ and GK wrote the manuscript, AS reviewed the manuscript.

\section{Acknowledgements}

This work was supported by a grant of the Medical Faculty, University of Pecs, Hungary (PTE-AOK-KA-2018/16). The Authors would like to thank Ms. Zsuzsanna Halas and Ms. Barbara Kanyo for their excellent technical assistance.

\section{References}

1 Levi F, Ferlay J, Galeone C, Lucchini F, Negri E, Boyle P and La Vecchia C: The changing pattern of kidney cancer incidence and mortality in Europe. BJU Int 101: 949-958, 2008. PMID: 18241251. DOI: 10.1111/j.1464-410X.2008.07451.x 
2 Chow WH, Dong LM and Devesa SS: Epidemiology and risk factors for kidney cancer. Nat Rev Urol 7: 245-257, 2010. PMID: 20448658. DOI: 10.1038/nrurol.2010.46

$3 \mathrm{Hu} \mathrm{B}$, Trinh K, Figueira WF and Price PA: Isolation and sequence of a novel human chondrocyte protein related to mammalian members of the chitinase protein family J Biol Chem 271: 19415-19420, 1996. PMID: 8702629. DOI: 10.1074/jbc.271.32.19415

4 Steck E, Breit S, Breusch SJ, Axt M and Richter W: Enhanced expression of the human chitinase 3-like 2 gene (YKL-39) but not chitinase 3-like 1 gene (YKL-40) in osteoarthritic cartilage. Biochem Biophys Res Commun 299: 109-115, 2002. PMID: 12435396. DOI: $10.1016 / \mathrm{s} 0006-291 \mathrm{x}(02) 02585-8$

5 Cintin C, Johansen JS, Christensen IJ, Price PA, Sørensen S and Nielsen HJ: High serum YKL-40 level after surgery for colorectal carcinoma is related to short survival. Cancer 95: 267274, 2002. PMID: 12124825. DOI: 10.1002/cncr.10644

6 Johansen JS, Drivsholm L, Price PA and Christensen IJ: High serum YKL-40 level in patient with small cell lung cancer is related to early death. Lung Cancer 46: 333-340, 2004. PMID: 15541818. DOI: 10.1016/j.lungcan.2004.05.010

7 Thorn AP, Daugaard S, Christensen LH, Christensen IJ and Petersen MM: YKL-40 protein in osteosarcoma tumor tissue. Apmis 124: 453-461, 2016. PMID: 26988273. DOI: 10.1111/apm.12524

8 Bi J, Lau SH, Lv ZL, Xie D, Li W, Lai YR, Lai YR, Zhong JM, Wu HQ, Su Q, He YL, Zhan WH, Wen JM and Guan XY: Overexpression of YKL-40 is and independent prognostic marker in gastric cancer. Hum Pathol 40: 1790-1797, 2009. PMID: 19765801. DOI: 10.1016/j.humpath.2009.07.005

9 Kzhyshkowska J, Yin S, Liu T, Riabov V and Mitrofanova I: Role of chitinase-like proteins in cancer. Biol Chem 397: 231247, 2016. PMID: 26733160. DOI: 10.1515/hsz-2015-0269

10 Paret C, Schön Z, Szponar A and Kovacs G: Inflammatory protein serum amyloid A1 marks a subset of conventional renal cell carcinomas with fatal outcome. Eur Urol 57: 859-866, 2009. PMID:19747761. DOI: 10.1016/j.eururo.2009.08.014

11 Subramanian A, Kuehn H, Gould J, Tarnayo P and Mesirov JP: GSEA-P: a desktop application for Gene Set Enrichment Analysis. Bioinformatics 23: 3251-3253, 2007. PMID: 17644 558. DOI: $10.1093 /$ bioinformatics/btm 369

12 Kovacs G, Akhtar M, Beckwith BJ, Bugert P, Cooper CS, Delahunt B, Eble JN, Fleming S, Ljungberg B, Medeiros LJ, Moch H, Reuter V, Ritz E, Roos G, Schmidt D, Srigley JR, Störkel S, van den Berg E and Zbar B: The Heidelberg classification of renal cell tumours. J Pathol 183: 131-133, 1997. PMID: 9390023. DOI: $10.1002 /($ S ICI ) 1096-9896(199710)183:2<131::AIDPATH931>3.0.CO;2-G

13 Brierly J, Gospodarowicz MK and Wittekind C (eds.). TNM Classification of Malignant tumours. John Wiley and Sons, 2017.

14 Renkema GH, Boot RG, Au FL, Donker-Koopman WE, Strijland A, Muijsers AO, Hrebicek M and Aerts JM: Chitotriosidase, a chitinase, and the 39-kDa human cartilage glycoprotein, a chitinbinding lectin, are homologues of family 18 glycosyl hydrolases secreted by human macrophages. Eur J Biochem 251: 504-509, 1998. PMID: 9492324. DOI: 10.1046/j.1432-1327.1998.2510504.x

15 Boot RG, Verhoek M, Donker-Koopman WE, Strijland A, van Merle J, Overkleeft HS, Wennekes $\mathrm{T}$ and Aerts JM: Identification of the non-lysosomal glucosylceramidase as betaglucosidase 2. J Biol Chem 282: 1305-1312, 2007. PMID: 17105727. DOI: $10.1074 /$ jbc.M610544200
16 Schimpl M, Rush CL, Betou M, Eggleston IM, Recklies AD and Van Alten DMF: Human YKL-39 is a pseudo-chitinase with retained chitooligosaccharide-binding properties. Biochem J 446: 149-157, 2012. PMID: 22742450. DOI: 10.1042/BJ20120377

17 Kavsan V, Dmitrenko V, Boyko O, Filonenko V, Avdeev S, Areshkov P, Marusyk A, Malisheva A, Rozumenko V and Zozuliya M: Overexpression of YKL-39 gene in glial brain tumors. Sch Res Exch 2008: 814849, 2008. DOI: 10.3814/2008/814849

18 Gratchev A, Kzhyshkowska J, Kannookadan S, Ochsenreiter M, Popova A, Yu X, Mamidi S, Stonehouse-Usselmann E, MullerMolinet I and Gooi L: Activation of a TGF-b-specific multistep gene expression program in mature macrophages requires glucocorticoid-mediated surface expression of TGF-b receptor II. J Immunol 180: 6553-6565, 2008. PMID: 18453574. DOI: 10.4049/jimmunol.180.10.6553

19 Areshkov PA and Kavsan VM: Chitinase 3-lke protein 2 (CHI3L2, YKL-39) activates phosphorylation of extracellular signal-regulated kinases ERK1/ERK2 in human embryonic kidney (HEK293) and human glioblastoma (U87 MG) cells. Tsito Genet 44: 3-9, 2010. PMID: 20201406.

20 Miyatake K, Tsuji K, Yamaga M, Yamada J, Matsukura Y, Abula K, Sekiya I and Muneta T: Human YKL-39 (chitinase 3-like protein 2), an osteoarthritis-associated gene, enhances proliferation and type II collagen expression in ATDC5 cells. Biochem Biophys Res Commun 431: 52-57, 2013. PMID: 23291184. DOI: 10.1016/j.bbrc.2012.12.094

21 Liu T, Larionova I, Litviakov N, Riabov V, Zavyalova M, Tsyganov M, Buldakov M, Song B, Moganti K, Kazantseva P, Slonimskaya E, Kremmer E, Flatley A, Klüter H, Cherdyntseva $\mathrm{N}$ and Kzhyshkowska J: Tumor associated macrophages in human breast cancer produces new monocyte attracting and proangiogenic factor YKL-39 indicative for increased metastasis after neoadjuvant chemotherapy. Oncoimmunology 7: e1436922, 2018. PMID: 29872578. DOI: 10.1080/2162402X.2018.1436922

22 Litviakov N, Tsyganov M, Larionova I, Ibragimova M, Deryusheva I, Kazantseva P, Slonimskaya E, Frolova I, Choinzonov E, Cherdintseva $\mathrm{N}$ and Kzhyshkowska J: Expression of M2 macrophage markers YKL-39 and CCL18 in brest cancer is associated with the effect of neoadjuvant therapy. Cancer Chemother Pharmacol 82: 99-109, 2018. PMID: 29728799. DOI: $10.1007 / \mathrm{s} 00280-018-3594-8$

23 Balkwill F, Charles KA and Mantovani A: Smoldering and polarized inflammation in the initiation and promotion of malignant disease. Cancer Cell 7: 211-217, 2005. PMID: 15766659. DOI: 10.1016/j.ccr.2005.02.013

24 Larionova I, Cherdyntseva N, Liu T, Patysheva M and Rakina $\mathrm{M}$ : Interaction of tumor-asociated macrophages and cancer chemotherapy. Oncoimmunology 8: e1596004, 2019. PMID: 31143517. DOI: $10.1080 / 2162402 X .2019 .1596004$
Received October 16, 2019

Revised October 31, 2019

Accepted November 4, 2019 